\title{
Analysis of troponin I gene polymorphisms and meat quality in Mongcai pigs
}

\author{
Nguyen Trong Ngu ${ }^{\#}$ \& Nguyen Thi Hong Nhan \\ College of Agriculture and Applied Biology, Cantho University, 3/2 Street, Cantho City, Vietnam
}

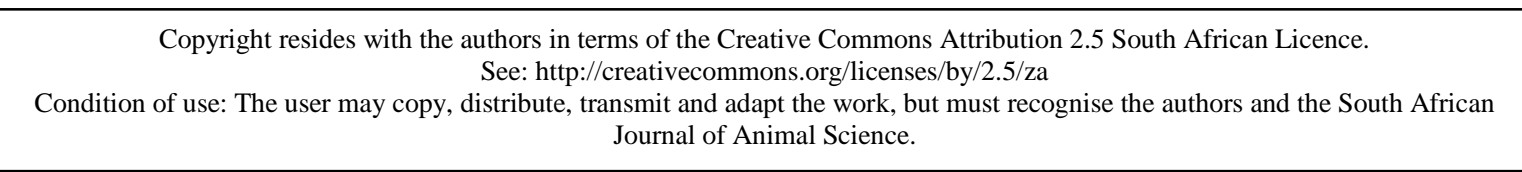

\begin{abstract}
Troponin I is one of myofibrillar proteins required for the calcium regulation of skeletal muscle contraction. The expression of both genes, TNNI1 and TNNI2, in troponin is muscle fibre specific and may affect meat quality traits. In this study, the PCR-RFLP method was applied to genotype 120 Mongcai pigs at three single-nucleotide polymorphisms (SNPs), namely T5174C, C8350A for TNNI1 (EU743939) and C1167T for TNNI2 (EU696779). The two SNPs, T5174C and C1167T, were significantly associated with drip loss $_{48}$ (measured after $48 \mathrm{~h}$ ) and compression force, while the second TNNI1 SNP (C8350A) did not show any association with meat quality traits. The results also revealed a relationship between the proportion of IIx muscle fibre and TNNI2. Additional analysis showed a significant association of the TNNI2 SNP (C1167T) with blood glucose. Animals carrying the CT genotype had the highest glucose concentration $(93.7 \mathrm{mg} / \mathrm{dL})$. The results demonstrate that TNNI1 and TNNI2 are likely to play a relatively important role in the development of pork quality in Mongcai pigs.
\end{abstract}

Keywords: TNNI1, TNNI2, drip loss, meat colour, pork, indigenous Vietnamese pigs

\#Corresponding author: ntngu@ctu.edu.vn

\section{Introduction}

Meat quality, a major contributor to the degree of satisfaction of consumers, is affected by several external and internal factors such as stress and types of muscle fibres, which are often linked to the genetic architecture of the animal. Increased demands of consumers have gradually shifted the emphasis of pig breeding programmes and selection criteria to improved meat quality, rather than on focusing only on lean carcasses and a high growth rate (Fiedler et al., 2003). Local pig breeds in Vietnam seem to be advantageous as they have poorer growth rates, but better meat quality compared with modern pig populations (Warriss et al., 1996). However, because meat quality can only be measured late in an animal's life, alternative selection criteria including the use of molecular markers have been explored and many candidate genes and other genetic markers have already been identified (Brym \& Kaminski, 2006).

The contractile protein, troponin, containing the three subunits, troponin I (TnI), troponin C (TnC) and troponin $\mathrm{T}(\mathrm{TnT})$, plays a role in the concentration of $\mathrm{Ca}^{2+}$, and is responsible for striated muscle contraction (Xu et al., 2010a). Each troponin has isoforms that are encoded by different genes. The troponin I genes, TNNI1 and TNNI2, are expressed exclusively in muscles of slow- and fast-twitch fibres, respectively (Mullen \& Barton, 2000). Both genes have been investigated as candidate genes for meat quality traits in a Large White x Meishan resource population (Yang et al., 2010). In that study the authors found associations between the T5174C SNP (TNNI1 gene) and intramuscular fat content, meat colour and marbling score, and between the T1167C SNP (TNNI2 gene) and pH and marbling score of the longissimus dorsi muscle. Although some studies have focused on TNNI gene variants, few studies have been published on their association with economically important traits such as meat quality in indigenous pigs. The objective of this study was to analyse the effects of three SNPs in the TNNI1 and TNNI2 genes with meat characteristics in Mongcai, one of the Vietnamese native pig breeds. 


\section{Materials and Methods}

A total of 120 Mongcai (MC) castrated males that had been reared on a state farm in the Quangninh Province of Vietnam, were slaughtered at $202 \pm 18$ days of age at a body weight of $28.6 \pm 6.2 \mathrm{~kg}$. During the feeding periods, animals were fed a diet containing $172 \mathrm{~g}$ crude protein (CP) $/ \mathrm{kg}$ and an energy content of 13.2 MJ ME/kg dry matter. They were fasted for $12 \mathrm{~h}$ and then slaughtered, following the standard commercial procedure, under the supervision of the veterinary service. Longissimus dorsi (LD) muscle samples (from the seventh thoracic vertebra to the last lumbar) were collected. A $2 \mathrm{~g}$ sample was kept in RNAlater (Qiagen) reagent for RNA isolation; a second sample was stored at $-20^{\circ} \mathrm{C}$ for DNA extraction and the remaining samples were used for meat quality evaluation.

At $24 \mathrm{~h}$ post mortem, meat colour, including $L^{*}$ (lightness), $a^{*}$ (redness) and $b^{*}$ (yellowness), was determined using a Minolta Chroma Meter (CR310, Minolta, Japan) on the cut surface. Muscle pH was measured at 45 min $\left(\mathrm{pH}_{45} \mathrm{~min}\right)$ and $24 \mathrm{~h}\left(\mathrm{pH}_{24}\right)$ post mortem with a Delta-320 portable $\mathrm{pH}$ meter (Richmond Scientific Ltd.). Drip loss was calculated as the weight loss of a meat sample collected at 45 min post mortem (40 $\pm 5 \mathrm{~g}$ ), placed in an inflated bag at $4{ }^{\circ} \mathrm{C}$ for $24 \mathrm{~h}$ (drip loss 24 ) and $48 \mathrm{~h}$ (drip loss 48 ) (Honikel, 1998). To obtain cooking loss, a loin cube $(90 \pm 5 \mathrm{~g})$ was taken and stored at $4^{\circ} \mathrm{C}$ for $24 \mathrm{~h}$, and subsequently bagged in thin-walled plastic and placed in a water bath at $75^{\circ} \mathrm{C}$ for $30 \mathrm{~min}$. The bag was then cooled under cold water for $30 \mathrm{~min}$ and cooking loss was expressed as the difference between the original weight and the cooked weight (Renaudeau \& Mourot, 2007). For compression force values, samples were thawed at $4{ }^{\circ} \mathrm{C}$ and cut into $10 \times 10 \mathrm{~mm}$ cross-sections (with the fibre direction) and six samples for each loin were measured using a TA - XT2i Texture Analyzer (Stable Micro Systems Ltd.) (Florowski et al., 2006). Blood collection was done during exsanguination to measure glucose concentrations by Glucose SD CodeFree (Standard Diagnostics Inc, Korea). The chemical composition of LD muscle such as dry matter, protein, ether extract and ash content was estimated by following protocols 950.46; 981.10; 960.39 and 920.153, respectively, of the AOAC (1998).

The total DNA of 120 samples was extracted according to the protocol described previously (Ngu, 2006). A DNA concentration of $50 \mathrm{ng} / \mu \mathrm{L}$ was used for further analyses. Primers and PCR conditions were adapted from Xu et al. (2010b). The PCR product was sequenced for confirmation of specificity and segregation of polymorphisms in the population. PCR-RFLP (restriction fragment length polymorphism) was applied using three restriction enzymes, $X b a \mathrm{I}, \mathrm{MspI}$ and SmaI, to genotype animals at the three SNPs, T5174C, C8350A (TNNI1) and C1167T (TNNI2), respectively (Xu et al., 2010b). In each PCR-RFLP reaction, a mix containing 1 unit of enzyme, $1 \mu \mathrm{L}$ of $10 \mathrm{x}$ restriction buffer and $1 \mu \mathrm{g}$ of PCR product was incubated at $37{ }^{\circ} \mathrm{C}$ for 15 min to ensure complete digestion. The digested product was checked by electrophoresis on a $2 \%$ agarose gel at $80 \mathrm{~V}$ for 1 hour.

Total RNA was isolated from individual LD samples of MC pigs, using the TRIzol ${ }^{\circledR}$ Reagent (Invitrogen, Karlsruhe, Germany) according to the manufacturer's protocol. Subsequently, cDNA was synthesized according to the instruction of the High Capacity RNA to cDNA Kit (Applied Biosystems). A real-time RT-PCR approach was applied, using five primer pairs from an earlier study (Wimmers et al., 2008) and the expression level of each fibre was determined based on the $2^{-\Delta \Delta \mathrm{Ct}}$ method described by Livak \& Schmittgen (2001). From this expression level, type IIb was assumed to be 1, and the relative ratios of types I, IIa and IIx to IIb were calculated as the corresponding expression of type I, IIa and IIx fibres. The muscle fibre percentage was then calculated from these proportions for each muscle type (Li et al., 2009). In total, $30 \mathrm{MC}$ pigs were used for muscle fibre typing.

The chi-square test was applied for testing if markers were in Hardy-Weinberg equilibrium (Rodriguez et al., 2009). Analysis of variance was performed using a general linear model in Minitab (version 13.20) to investigate the effect of genotypes on meat quality traits. Factors found to affect the traits such as genotype, boar, sow and slaughter weight were used in the model. A $P$-value less than 0.05 was deemed the significant threshold using the Tukey option in the least square procedure.

\section{Results and Discussion}

Animals were genotyped at two loci in the TNNI1 gene and one in the TNNI2 gene, and the PCR product sizes were 190, 320 and 425 bp, respectively. All three SNPs, T5174C (TNNI1_XbaI), C8350A (TNNI1_MspI) and C1167T (TNNI2_SmaI) were segregated in the animals from the MC population (Figure 1). 


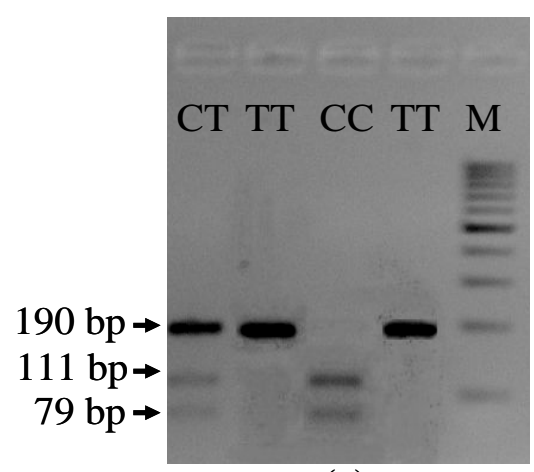

(a)

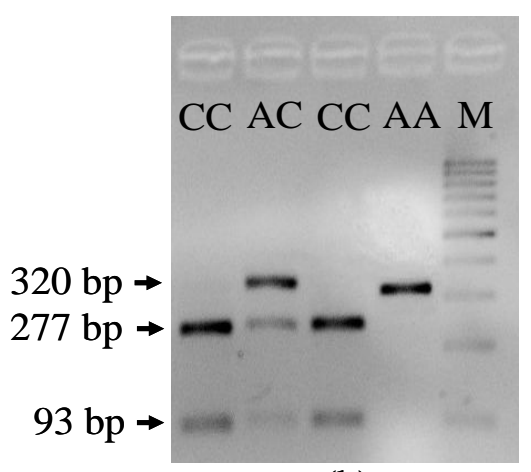

(b)

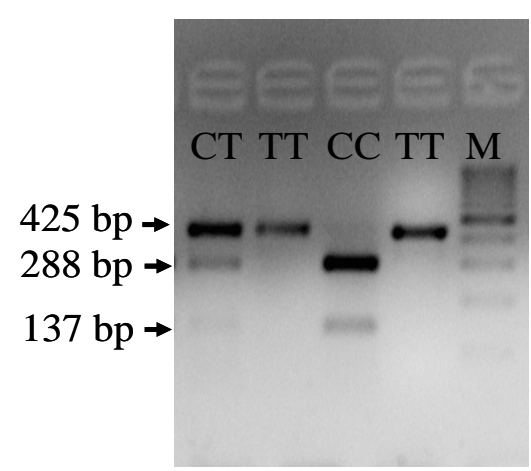

(c)

Figure 1 Agarose gel electrophoresis of PCR-RFLP: (a) TNNI1_XbaI, (b) TNNI1_MspI and (c) TNNI2_SmaI, M: 100 bp Fermentas Marker.

Digestion of the TNNI1 PCR product with XbaI produced three fragments (Figure 1a), two of which were 111 and $79 \mathrm{bp}$, where the presence of the base $C$ was recognised by the enzyme. The $190 \mathrm{bp}$ product showed that alleles with the alternative base $\mathrm{T}$ were not cut. The corresponding genotype frequencies were 0.15, 0.49 and 0.36 for CC, CT and TT, respectively (Table 1 ) and the animals were in Hardy-Weinberg equilibrium $(P>0.05)$ at the TNNI1_XbaI locus. Similarly, alleles of animals carrying the base C at the second TNNI1 SNP (TNNI1_MspI) were cut by the enzyme, resulting in two bands of 277 and 93 bp length, while alleles carrying $\mathrm{A}$ at the enzyme recognition site showed only one $320 \mathrm{bp}$ fragment on agarose gel (Figure 1b). The frequencies of AA, AC and CC genotypes were 0.52, 0.25 and 0.23 , respectively. Genotyping of individuals at the TNNI2 (TNNI2_SmaI) locus distinguished between three genotypes with visualised fragment sizes of 425 bp (TT), 288 and 137 bp (CC) and 425, 288 and 137 bp (CT) (Figure 1c). In addition, it was found that the animals chosen for this study were not in Hardy-Weinberg equilibrium at both loci $(P<0.001)$. The current findings corroborate the results of Xu et al. (2010b), who detected two SNPs in the TNNI1 gene in indigenous Meishan pigs with higher frequencies of T (T5174C) and A (C8350A) alleles ( 0.86 and 0.76 , respectively) while studies using commercial pigs, revealed a higher percentage of animals carrying the C allele (Xu et al., 2010b).

Table 1 Genotype and allele frequencies of three SNPs in MC pigs

\begin{tabular}{|c|c|c|c|c|c|c|c|c|}
\hline \multirow{3}{*}{$\begin{array}{c}\text { SNPs } \\
\text { TNNI1_XbaI } \\
\text { T5174C }\end{array}$} & \multicolumn{3}{|c|}{ Observed genotypes $^{1}$} & \multirow[t]{2}{*}{ Total } & \multicolumn{2}{|c|}{ Allelic frequencies } & \multirow[t]{2}{*}{$\mathrm{X}(\mathrm{HW})$} & \multirow[t]{2}{*}{$P(\mathrm{HW})$} \\
\hline & CC & CT & TT & & C & $\mathrm{T}$ & & \\
\hline & $0.15(18)$ & $0.49(59)$ & $0.36(43)$ & 120 & 0.40 & 0.60 & 0.094 & 0.954 \\
\hline TNNI1_MspI & AA & AC & $\mathrm{CC}$ & & A & $\mathrm{C}$ & & \\
\hline C8350A & $0.52(57)$ & $0.25(27)$ & $0.23(25)$ & 109 & 0.65 & 0.35 & 22.850 & 0.000 \\
\hline TNNI2_SmaI & CC & CT & TT & & C & $\mathrm{T}$ & & \\
\hline C1167T & 0.57 (69) & 0.27 (32) & $0.16(19)$ & 120 & 0.71 & 0.29 & 15.091 & 0.000 \\
\hline
\end{tabular}

The TNNI1_XbaI genotypes showed an association $(P<0.05)$ with drip loss $_{48}$, compression force and crude protein content whereas no significant association was found for TNNI1_MspI (Table 2). Animals carrying the CC genotype at locus TNNI1_XbaI exhibited the highest drip loss percentage at 48 h post mortem (3.36\%) followed by TT and CT $(2.83 \%$ and $2.43 \%$, respectively). An association $(P<0.05)$ was also found for compression force; meat from TT animals appeared to be tender with a lower compression force $(4.70 \mathrm{~kg})$. Also the CP values were higher in the MC loin muscle of pigs with TT genotypes compared 
to CC animals. No statistical association could be shown for the second TNNI1 locus, TNNI1_MspI (Table 2).

Table 2 Association of TNNI1 SNPs with meat quality traits (LSM \pm SE)

\begin{tabular}{|c|c|c|c|c|c|c|}
\hline \multirow{2}{*}{ Trait } & \multicolumn{3}{|c|}{ TNNI1_XbaI } & \multicolumn{3}{|c|}{ TNNI1_MspI } \\
\hline & $\mathrm{CC}(\mathrm{n}=18)$ & $\mathrm{CT}(\mathrm{n}=59)$ & $\mathrm{TT}(\mathrm{n}=43)$ & $\mathrm{AA}(\mathrm{n}=57)$ & $\mathrm{AC}(\mathrm{n}=27)$ & CC $(n=25)$ \\
\hline $\mathrm{pH}_{45 \min }$ & $6.57 \pm 0.06$ & $6.61 \pm 0.04$ & $6.68 \pm 0.04$ & $6.68 \pm 0.04$ & $6.60 \pm 0.04$ & $6.58 \pm 0.06$ \\
\hline $\mathrm{pH}_{24}$ & $6.16 \pm 0.06$ & $6.19 \pm 0.04$ & $6.23 \pm 0.04$ & $6.20 \pm 0.04$ & $6.21 \pm 0.05$ & $6.28 \pm 0.06$ \\
\hline Drip $\operatorname{loss}_{24}(\%)$ & $2.27 \pm 0.25$ & $1.81 \pm 0.15$ & $1.96 \pm 0.17$ & $1.85 \pm 0.17$ & $2.26 \pm 0.22$ & $1.88 \pm 0.25$ \\
\hline Drip loss 48 (\%) & $3.36^{\mathrm{a}} \pm 0.30$ & $2.43^{\mathrm{b}} \pm 0.18$ & $2.83^{\mathrm{ab}} \pm 0.20$ & $2.66 \pm 0.20$ & $3.15 \pm 0.26$ & $2.74 \pm 0.29$ \\
\hline Cooking loss (\%) & $22.82 \pm 1.34$ & $22.56 \pm 0.81$ & $23.56 \pm 0.88$ & $22.47 \pm 0.82$ & $23.71 \pm 1.10$ & $22.22 \pm 1.21$ \\
\hline Compression force (kg) & $5.23^{\mathrm{ab}} \pm 0.48$ & $5.74^{\mathrm{a}} \pm 0.29$ & $4.70^{\mathrm{b}} \pm 0.32$ & $5.35 \pm 0.33$ & $5.11 \pm 0.43$ & $5.70 \pm 0.49$ \\
\hline \multicolumn{7}{|l|}{ Meat colour } \\
\hline$L^{*}$ (lightness) & $49.66 \pm 0.48$ & $49.32 \pm 0.29$ & $49.06 \pm 0.32$ & $49.03 \pm 0.30$ & $49.32 \pm 0.40$ & $49.12 \pm 0.44$ \\
\hline$a^{*}$ (redness) & $5.34 \pm 0.84$ & $5.62 \pm 0.51$ & $5.85 \pm 0.56$ & $6.19 \pm 0.52$ & $5.39 \pm 0.69$ & $4.88 \pm 0.77$ \\
\hline$b^{*}$ (yellowness) & $9.10 \pm 0.42$ & $9.04 \pm 0.26$ & $8.44 \pm 0.28$ & $8.67 \pm 0.27$ & $8.56 \pm 0.36$ & $9.43 \pm 0.40$ \\
\hline \multicolumn{7}{|l|}{ Nutritional value } \\
\hline Dry matter (\%) & $25.6 \pm 0.41$ & $25.6 \pm 0.25$ & $25.8 \pm 0.27$ & $25.9 \pm 0.26$ & $25.2 \pm 0.34$ & $25.4 \pm 0.39$ \\
\hline Crude protein (\%) & $21.4^{\mathrm{b}} \pm 0.30$ & $22.0^{\mathrm{ab}} \pm 0.18$ & $22.4^{\mathrm{a}} \pm 0.20$ & $21.9 \pm 0.21$ & $22.3 \pm 0.27$ & $22.0 \pm 0.31$ \\
\hline Ether extract (\%) & $2.57 \pm 0.16$ & $2.60 \pm 0.10$ & $2.50 \pm 0.11$ & $2.61 \pm 0.11$ & $2.46 \pm 0.14$ & $2.49 \pm 0.16$ \\
\hline Ash (\%) & $1.03 \pm 0.11$ & $1.00 \pm 0.07$ & $1.05 \pm 0.07$ & $1.11 \pm 0.07$ & $0.95 \pm 0.09$ & $1.00 \pm 0.10$ \\
\hline
\end{tabular}

${ }^{\mathrm{a}, \mathrm{b}}$ Row means with different superscripts differ significantly at $P<0.05$.

An association was additionally observed between the TNNI2 (TNNI2_SmaI) locus and drip $\operatorname{loss}_{48}(P$ $=0.002)$. This locus also showed some effect $(P=0.057)$ on drip loss at $24 \mathrm{~h}$ (Table 3$)$.

Many factors, such as genetics, carcass handling, temperature management post mortem, nutrition and meat processing have been investigated as factors influencing drip loss, with the physiological mechanism mainly centred on proteins (specially myofibrillar protein) and structures binding and entrapping water (Huff-Lonergan \& Lonergan, 2005; Jennen et al., 2007). In the present study, both TNNI1_XbaI and TNNI2_SmaI loci were associated with drip $\operatorname{loss}_{48}$ but it seems not likely that the effect of the genes originates from their impact on muscle fibre type composition, as suggested by Ryu \& Kim (2005). These authors suggested that increased IIb fibre content together with decreased type I and IIa fibre content were linked to higher drip loss, and therefore leading to poorer meat quality (Ryu \& Kim, 2005). In the present study, variation of drip loss and type IIx fibre muscle of the TNNI2_SmaI polymorphism appeared to have a negative relationship, especially in heterozygous animals (CT). This was partly in line with the outputs of Chang et al. (2003), who presented both negative and positive correlations of the IIx fibre with drip loss in traditional breeds of Berkshire and Tamworth, respectively. Different pig breeds have their own biochemical and biophysical properties and because IIx is an intermediate fibre, its characteristics are more prone to IIa, or IIb fibres are dependent on the metabolic condition of the breed (Chang et al., 2003). Additionally, Yang et al. (2010) could not find any significant difference of the genotypes in relation to drip loss or water holding capacity while our results, in the contrary, showed the effects of TNNI1 and TNNI2 on pH, meat colour and intramuscular fat, of which heterozygous pigs had an inferior meat quality in terms of lower meat $\mathrm{pH}$ and intramuscular fat content. The lack of consistency on the association may be that these SNPs are not causative mutations and that the effects are breed-specific for the traits analysed. 
Table 3 Association of TNNI2 SNP with meat quality traits (LSM \pm SE)

\begin{tabular}{lcccc}
\hline \multirow{2}{*}{ Trait } & \multicolumn{3}{c}{ TNNI2_SmaI } & \multirow{2}{*}{$P$} \\
\cline { 2 - 4 } & CC (n=69) & CT (n=32) & TT (n=19) & \\
\hline $\mathrm{pH}_{45 \text { min }}$ & $6.62 \pm 0.04$ & $6.61 \pm 0.05$ & $6.67 \pm 0.07$ & 0.774 \\
$\mathrm{pH}_{24}$ & $6.22 \pm 0.03$ & $6.13 \pm 0.04$ & $6.22 \pm 0.06$ & 0.180 \\
Drip loss $_{24}$ (\%) & $2.02 \pm 0.15$ & $1.56 \pm 0.19$ & $2.19 \pm 0.26$ & 0.057 \\
Drip loss 48 (\%) & $2.80^{\mathrm{a}} \pm 0.18$ & $2.12^{\mathrm{b}} \pm 0.23$ & $3.36^{\mathrm{a}} \pm 0.31$ & 0.002 \\
Cooking loss (\%) & $23.73 \pm 0.81$ & $22.10 \pm 1.02$ & $22.27 \pm 1.36$ & 0.325 \\
Compression force (kg) & $5.20 \pm 0.31$ & $5.36 \pm 0.38$ & $5.25 \pm 0.51$ & 0.935 \\
Meat colour & & & & \\
$\quad L^{*}$ (lightness) & $49.20 \pm 0.29$ & $49.54 \pm 0.37$ & $49.15 \pm 0.49$ & 0.675 \\
$\quad a^{*}$ (redness) & $5.29 \pm 0.51$ & $5.84 \pm 0.64$ & $6.36 \pm 0.86$ & 0.515 \\
$\quad b^{*}$ (yellowness) & $8.97 \pm 0.26$ & $8.79 \pm 0.32$ & $8.50 \pm 0.44$ & 0.642 \\
Chemical composition & & & & \\
$\quad$ Dry matter (\%) & $25.6 \pm 0.25$ & $26.1 \pm 0.31$ & $25.2 \pm 0.42$ & 0.244 \\
$\quad$ Crude protein (\%) & $21.9 \pm 0.20$ & $22.3 \pm 0.25$ & $22.0 \pm 0.34$ & 0.398 \\
$\quad$ Ether extract (\%) & $2.56 \pm 0.10$ & $2.54 \pm 0.13$ & $2.56 \pm 0.17$ & 0.989 \\
$\quad$ Ash (\%) & $1.03 \pm 0.06$ & $0.93 \pm 0.08$ & $1.16 \pm 0.11$ & 0.210 \\
\hline a,b Row means with different superscripts differ significantly at $P<0.05$ &
\end{tabular}

${ }^{\mathrm{a}, \mathrm{b}}$ Row means with different superscripts differ significantly at $P<0.05$.

Table 4 Relationship between three SNPs and muscle fibre type composition (LSM \pm SE)

\begin{tabular}{|c|c|c|c|c|c|c|c|c|c|}
\hline \multirow{2}{*}{$\begin{array}{c}\text { Muscle fibre } \\
\text { composition } \\
(\%)\end{array}$} & \multicolumn{3}{|c|}{ TNNI1_XbaI } & \multicolumn{3}{|c|}{ TNNI1_MspI } & \multicolumn{3}{|c|}{ TNNI2_SmaI } \\
\hline & $\begin{array}{c}\text { CC } \\
(\mathrm{n}=5)\end{array}$ & $\begin{array}{c}\text { CT } \\
(\mathrm{n}=13)\end{array}$ & $\begin{array}{c}\text { TT } \\
(\mathrm{n}=12)\end{array}$ & $\begin{array}{c}\text { AA } \\
(n=16)\end{array}$ & $\begin{array}{c}\text { AC } \\
(\mathrm{n}=8)\end{array}$ & $\begin{array}{c}\text { CC } \\
(n=2)\end{array}$ & $\begin{array}{c}\text { CC } \\
(n=16)\end{array}$ & $\begin{array}{c}\text { CT } \\
(\mathrm{n}=8)\end{array}$ & $\begin{array}{c}\mathrm{TT} \\
(\mathrm{n}=6)\end{array}$ \\
\hline Type I & $\begin{array}{c}22.7 \\
( \pm 3.0)\end{array}$ & $\begin{array}{c}23.2 \\
( \pm 4.4)\end{array}$ & $\begin{array}{c}23.4 \\
( \pm 4.1)\end{array}$ & $\begin{array}{c}23.8 \\
( \pm 3.9)\end{array}$ & $\begin{array}{c}22.9 \\
( \pm 4.5)\end{array}$ & $\begin{array}{c}23.1 \\
( \pm 6.2)\end{array}$ & $\begin{array}{c}24.5 \\
( \pm 3.5)\end{array}$ & $\begin{array}{c}22.3 \\
( \pm 4.4)\end{array}$ & $\begin{array}{c}21.9 \\
( \pm 4.6)\end{array}$ \\
\hline Tyре IIa & $\begin{array}{c}27.9 \\
( \pm 4.3)\end{array}$ & $\begin{array}{c}27.3 \\
( \pm 3.7)\end{array}$ & $\begin{array}{c}25.4 \\
( \pm 5.5)\end{array}$ & $\begin{array}{c}25.4 \\
( \pm 5.2)\end{array}$ & $\begin{array}{c}27.3 \\
( \pm 2.8)\end{array}$ & $\begin{array}{c}30.4 \\
( \pm 0.3)\end{array}$ & $\begin{array}{c}27.7 \\
( \pm 3.9)\end{array}$ & $\begin{array}{c}25.3 \\
( \pm 3.2)\end{array}$ & $\begin{array}{c}26.4 \\
( \pm 7.3)\end{array}$ \\
\hline Type IIx & $\begin{array}{c}38.0 \\
( \pm 3.2)\end{array}$ & $\begin{array}{c}38.3 \\
( \pm 4.3)\end{array}$ & $\begin{array}{c}39.1 \\
( \pm 5.2)\end{array}$ & $\begin{array}{c}38.5 \\
( \pm 4.6)\end{array}$ & $\begin{array}{c}39.4 \\
( \pm 5.2)\end{array}$ & $\begin{array}{c}37.2 \\
( \pm 6.2)\end{array}$ & $\begin{array}{c}36.4^{\mathrm{b}} \\
( \pm 3.0)\end{array}$ & $\begin{array}{c}41.0^{\mathrm{a}} \\
( \pm 4.0)\end{array}$ & $\begin{array}{c}39.5^{\mathrm{ab}} \\
( \pm 5.8)\end{array}$ \\
\hline Type IIb & $\begin{array}{c}11.3 \\
( \pm 1.6)\end{array}$ & $\begin{array}{c}11.2 \\
( \pm 2.5)\end{array}$ & $\begin{array}{c}12.1 \\
( \pm 3.4)\end{array}$ & $\begin{array}{c}12.3 \\
( \pm 3.1)\end{array}$ & $\begin{array}{c}10.4 \\
( \pm 1.7)\end{array}$ & $\begin{array}{c}9.3 \\
( \pm 0.3)\end{array}$ & $\begin{array}{c}11.4 \\
( \pm 2.9)\end{array}$ & $\begin{array}{c}11.4 \\
( \pm 2.1)\end{array}$ & $\begin{array}{c}12.3 \\
( \pm 3.4)\end{array}$ \\
\hline
\end{tabular}

${ }^{\mathrm{a}, \mathrm{b}}$ Row means with different superscripts differ significantly at $P<0.05$.

Four out of eight isoforms known in mammals have been identified in porcine muscle according to their specific expression of the myosin heavy chain (Chang \& Fernandes, 1997). Based on their metabolic and myosin adenosine triphosphatase (mATPase) activity, these fibres are categorized as slow-oxidative and fast-glycolytic or slow/I and IIb fibres, standing for extreme metabolic profiles. The IIa and IIx fibres are defined as intermediates with the transition that IIa fibres are more similar to slow/I type and IIx fibres are more in relation to IIb fibres (Pette \& Staron, 2000; Chang et al., 2003). Expression and sequence of troponin I appeared to be linked to different muscle fibre isoforms, since Furukawa \& Peter (1971) stated that troponin activity in skeletal muscle of guinea pigs is related to three histochemical fibres in such a way that intermediate and red fibres have lower troponin activities compared to white fibres. To verify this 
phenomenon, an additional analysis on the relationship between genotypes and muscle fibre composition was done in 30 MC animals. However, no significant association could be shown between the TNNI1 genotypes and fibre type composition, whereas at the TNNI2_SmaI locus, heterozygous animals produced more IIx fibres (41.0\%) compared to the homozygous TT (39.5\%) and CC (36.4\%) animals (Table 4).

The texture of meat is usually evaluated by shear force and compression force; both traits display sensory quality. In the current study, it was observed that the compression force necessary to cut the meat was lowest in animals carrying the TT genotype at the TNNI1_XbaI locus. Generally, the texture of meat depends on the intramuscular fat; a higher fat content is usually correlated with greater tenderness or lower compression force (Florowski et al., 2006). The TNNI2 locus showed significant association with the amount of IIx fibre but no effect on meat tenderness measured by compression force value could be shown. The results from the association study for the two significant loci TNN1_XbaI and TNNI2_SmaI supported previous findings of low or unclear phenotypic correlations between muscle fibres and compression force (Wojtysiak \& Migdal, 2007). Although muscle fibre type composition has been considered as a useful parameter to partly explain the variation of meat quality traits, the direct effect remained unclear and it could be the case in the present study that the association of genotypes of TNNI1 and TNNI2 genes with drip loss and compression force may derive from other meat characteristics including sarcoplasmic protein, muscle enzymes and connective tissue (Do et al., 2008) rather than the percentages of muscle fibre in LD muscle. Nevertheless, these associations implied that MC pigs carrying the T allele at the TNNI1_XbaI locus are likely to have a better meat quality.

In this study a significant effect on blood glucose could only be shown for the TNNI2_SmaI locus; heterozygous MC pigs had the highest blood glucose concentrations (93.7 mg/dL) (Figure 2).

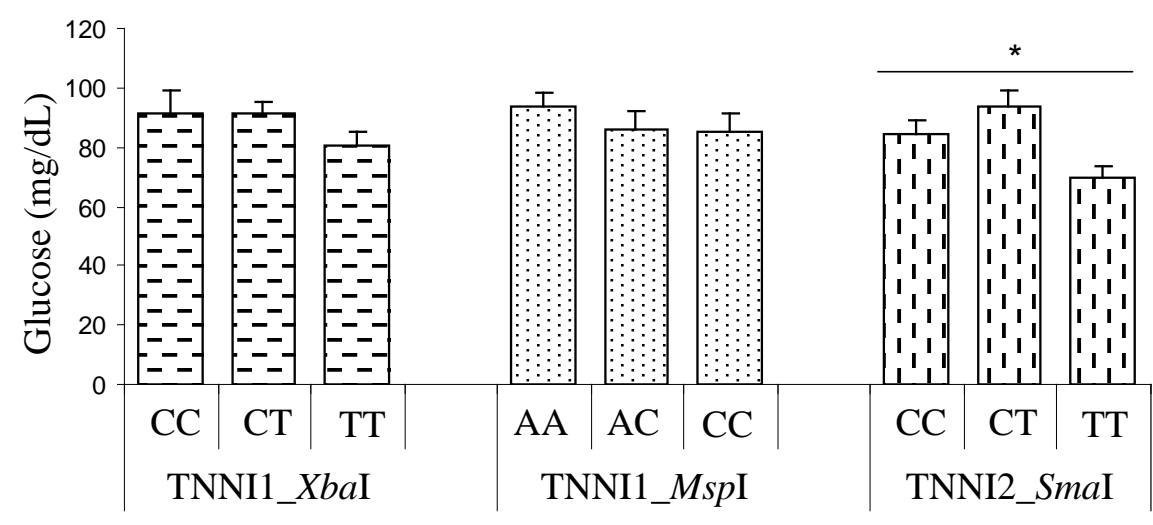

Figure 2 Effects of SNPs on blood glucose $(\mathrm{n}=89)$.* Significant difference at $P<0.05$.

A higher proportion of IIb fibre has been shown to be related to greater glycolytic activity and as a consequence higher glucose concentrations can be expected (Karlsson et al., 1999). Choe et al. (2009) later confirmed this by classifying white fibre (IIx and IIb) by histochemical analysis and reporting a correlation between blood glucose levels and area percentages of these fibres. Also, in MC pigs (Table 4), heterozygous animals at the TNNI2_SmaI locus had a higher percentage of IIx and IIb fibres (52.4\%) and higher blood glucose levels, suggesting that blood glucose could be a potential bio-marker for the prediction of muscle fibre composition.

\section{Conclusions}

Among the three loci examined, TNNI1_XbaI and TNNI2_SmaI SNPs provide some evidence on the potential use as markers for meat quality traits such as drip loss and compression force in Mongcai pigs. However, as suggested by Xu et al. (2010b) and Yang et al. (2010) further studies are needed to investigate the effect of these SNPs also in combination with surrounding genes, for instance, the IGF2 (Insulin-like Growth Factor 2) mutation. 


\section{Acknowledgements}

This project was supported financially by Vietnam's National Foundation for Science and Technology Development (NAFOSTED), Grant No. 106.06.62.09.

\section{References}

AOAC, 1998. Official Methods of Analysis (16 ${ }^{\text {th }}$ ed.). Association of Official Analytical Chemists, Inc., Arlington, Virginia, USA.

Brym, P. \& Kaminski, S., 2006. Database of SNPs in candidate genes potentially associated with yield and quality of pork. Anim. Sci. Pap. Rep. 24, 239-257.

Chang, K.C., da Costa, N., Blackley, R., Southwood, O., Evans, G., Plastow, G., Wood, J.D. \& Richardson, R.I., 2003. Relationships of myosin heavy chain fiber types to meat quality traits in traditional and modern pigs. Meat Sci. 64, 93-103.

Chang, K.C. \& Fernandes, K., 1997. Developmental expression and 5' end cDNA cloning of the porcine 2x and 2b myosin heavy chain genes. DNA Cell Biol. 16, 1429-1437.

Choe, J.H., Choi, Y.M., Lee, S.H., Nam, Y.J., Jung, Y.C., Park, H.C., Kim, Y.Y. \& Kim, B.C., 2009. The relation of blood glucose level to muscle fiber characteristics and pork quality traits. Meat Sci. 83, 62-67.

Do, K.T., Ha, Y., Mote, B.E., Rothschild, M.F., Choi, B.H., Lee, S.S., Kim, T.H., Cho, B.W. \& Kim, K.S., 2008. Investigation of single nucleotide polymorphisms in porcine chromosome 2 quantitative trait loci for meat quality traits. Asian-Aust. J. Anim. Sci. 21, 155-160.

Fiedler, I., Nurnberg, K., Hardge, T., Nurnberg, G. \& Ender, K., 2003. Phenotypic variations of muscle fiber and intramuscular fat traits in longissimus muscle of F2 population Duroc x Berlin Miniature Pig and relationships to meat quality. Meat Sci. 63, 131-139.

Florowski, T., Pisula, A., Adamczak, L., Buczynski, J.T. \& Orzechowska, B., 2006. Technological parameters of meat in pigs of two Polish local breeds-Zlotnicka Spotted and Pulawska. Anim. Sci. Pap. Rep. 24, 217-224.

Furukawa, T. \& Peter, J.B., 1971. Troponin activity of different types of muscle fibers. Exp. Neurol. 31, 214-222.

Honikel, K.O., 1998. Reference methods for the assessment of physical characteristics of meat. Meat Sci. 49, 447-457.

Huff-Lonergan, E. \& Lonergan, S.M., 2005. Mechanisms of water-holding capacity of meat: The role of post mortem biochemical and structural changes. Meat Sci. 71, 194-204.

Jennen, D.G.J., Brings, A.D., Liu, G., Juengst, H., Tholen, E., Jonas, E., Tesfaye, D., Schellander, K. \& Phatsara, C., 2007. Genetic aspects concerning drip loss and water-holding capacity of porcine meat. J. Anim. Breed. Genet. 124, 2-11.

Karlsson, A.H., Klont, R.E. \& Fernandez, X., 1999. Skeletal muscle fibers as factors for pork quality. Livest. Prod. Sci. 60, 255-269.

Li, X., Yang, X., Shan, B., Shi, J., Xia, D., Wegner, J. \& Zhao, R., 2009. Meat quality is associated with muscle metabolic status but not contractile myofiber type composition in premature pigs. Meat Sci. 81, 218-223.

Livak, K.J. \& Schmittgen, T.D., 2001. Analysis of relative gene expression data using real-time quantitative PCR and the $2^{-\Delta \Delta \mathrm{Ct}}$ method. Methods 25, 402-408.

Mullen, A.J. \& Barton, P.J.R., 2000. Structural characterization of the human fast skeletal muscle troponin I gene (TNNI2). Gene 242, 313-320.

Ngu, N.T., 2006. Transcript abundance of myosin heavy chain isoforms and identification of candidate genes for body composition and meat quality in pigs. Doctorial thesis, University of Bonn, Bonn, Germany, http://hss.ulb.uni-bonn.de/diss_online/landwfak/2006/ngu_nguyen/.

Pette, D. \& Staron, R.S., 2000. Myosin isoforms, muscle fiber types, and transitions. Microsc. Res. Tech. 50, 500-509.

Renaudeau, D. \& Mourot, J., 2007. A comparison of carcass and meat quality characteristics of Creole and Large White pigs slaughtered at $90 \mathrm{~kg}$ BW. Meat Sci. 76, 165-171.

Rodriguez, S., Gaunt, T.R. \& Day, I.N.M., 2009. Hardy-Weinberg equilibrium testing of biological ascertainment for Mendelian randomization studies. Am. J. Epidemiol. 169, 505-514. 
Ryu, Y.C. \& Kim, B.C., 2005. The relationship between muscle fiber characteristics, post mortem metabolic rate, and meat quality of pig longissimus dorsi muscle. Meat Sci. 71, 351-357.

Warriss, P.D., Kestin, S.C., Brown, S.N. \& Nute, G.R., 1996. The quality of pork from traditional pig breeds. Meat Focus International 5.

Wimmers, K., Ngu, N.T., Jennen, D.G.J., Tesfaye, D., Murani, E., Schellander, K. \& Ponsuksili, S., 2008. Relationship between myosin heavy chain isoform expression and muscling in several diverse pig breeds. J. Anim. Sci. 86, 795-803.

Wojtysiak, D. \& Migdal, W., 2007. Differences in muscle fiber composition and tenderness of m. longissimus lumborum between heterozygous and homozygous negative Polish Landrace pigs for the RYR1. Arch. Tierz, Special Issue, 186-193.

Xu, Z.Y., Yang, H., Li, Y., Xiong, Y.Z. \& Zuo, B., 2010a. Temporal expression of TnI fast and slow isoforms in biceps femoris and masseter muscle during pig growth. Animal 4, 1541-1546.

Xu, Z.Y., Yang, H., Xiong, Y.Z., Deng, C.Y., Li, F.E., Lei, M.G. \& Zuo, B., 2010b. Identification of three novel SNPs and association with carcass traits in porcine TNNI1 and TNNI2. Mol. Biol. Rep. 37, 3609-3613.

Yang, H., Xu, Z.Y., Lei, M.G., Li, F.E., Deng, C.Y., Xiong, Y.Z. \& Zuo, B., 2010. Association of 3 polymorphisms in porcine troponin I genes (TNNI1 and TNNI2) with meat quality traits. J. Appl. Genet. 51, 51-57. 